http://jmscr.igmpublication.org/home/ ISSN (e)-2347-176x ISSN (p) 2455-0450 crossref DOI: https://dx.doi.org/10.18535/jmscr/v8i5.34

\title{
Food Security and the Coronavirus Disease 2019 (COVID-19): A Systemic Review
}

\author{
Authors \\ Dr Md. Shafiur Rahman ${ }^{1}$, Dr Irin Hossain ${ }^{2}$, Dr Ashekur Rahman Mullick ${ }^{3}$, \\ Prof Dr Manzurul Haque Khan, $\mathrm{PhD}^{4}$ \\ ${ }^{1,2,4}$ National Institute of Preventive and Social Medicine, Dhaka, Bangladesh \\ ${ }^{3}$ Delta Medical College and Hospital, Dhaka, Bangladesh \\ *Corresponding Author \\ Dr Irin Hossain
}

\begin{abstract}
This review study aims at discussing about the status of food security during COVID-19.The Coronavirus (COVID-19) pandemic is disrupting the world with a heavy toll on human lives and economic activities. Its rapid global spread is threatening to affect millions of people already made vulnerable by food insecurity, malnutrition and the effects of conflict and other disasters. It was a systemic review study regarding global food security status due to COVID-19. We gather total 29 articles and web portals information related to COVID-19 and food security using different search portal like PubMed, Google Scholar, Nature, and Lancet. After proper literature review only 9 literatures and web portals information which were related to this study were taken for this systemic review purpose. The devastating economic impacts of COVID-19 reinforce the need for investments that prevent future outbreaks of such infectious diseases, recognizing the interconnections between people, animals, plants and their shared environment - the One Health approach. Continued attention is necessary strengthen the resilience of food systems to such disease outbreaks but also to other shocks.
\end{abstract}

Keywords: Food Security, The Coronavirus Disease, COVID-19.

\section{Introduction}

The Coronavirus (COVID-19) pandemic is disrupting the world with a heavy toll on human lives and economic activities. Its rapid global spread is threatening to affect millions of people already made vulnerable by food insecurity, malnutrition and the effects of conflict and other disasters ${ }^{1}$. Currently, some 820 million people around the world are experiencing chronic hunger, not eating enough caloric energy to live normal lives. Of these, 113 million are coping with acute severe insecurity, hunger so severe that it poses an immediate threat to their lives or livelihoods and renders them reliant on external assistance to survive. These people can illafford any potential further disruptions to their livelihoods or access to food that COVID-19 might 
bring. If COVID-19 cases, already present in most world regions, proliferate in the 44 countries that need external food assistance - or in the 53 countries home to 113 million people experiencing acute severe food insecurity, many of whose public health and social protection systems face capacity constraints the consequences could be drastic. Quarantines and panic during the Ebola Virus Disease outbreak in Sierra Leone (2014-2016), for example, led to a spike in hunger and malnutrition. The suffering worsened as restrictions on movement led both to labour shortages at harvest time even as other farmers were unable to bring their produce to market. The systemic effect was akin to that of an earthquake, highlighting how prevention and risk reduction strategies now are paramount. Food demand is generally inelastic and its effect on overall consumption will be likely limited, although dietary patterns may alter. There is a possibility of a disproportionately larger decline in animal protein consumption (as a result of fears, not science-based and that animals might be hosts of the virus, and other higher valued products like fish, fruits and vegetables (which are likely to cause price slumps). These fears can be particularly true for raw fish products supplied to restaurants and hotels, including small and medium enterprises. Food demand in poorer countries is more linked to income, and, here, loss of income-earning opportunities could impact on consumption. Fear of contagion can translate in reduced visits to food markets, and we expect to see a shift in how people buy and consume food - lower restaurant traffic, increased e-commerce deliveries (as evidenced in China), and a rise in eating at home. Following the outbreak of coronavirus, countries around the world started to implement a number of policy measures aimed at avoiding the further spread of the disease. However, such measures might affect agricultural production and trade. For instance, many countries are implementing higher controls on cargo vessels, with the risk of jeopardizing shipping activities and with a particular risk to perishable goods, like fresh fruits and vegetables, fish and fish products. Measures affecting the free movement of people, such as seasonal workers, might have an impact on food production, thus affecting market prices globally. Measures to guarantee acceptable health standards in food factories, may slow down production ${ }^{2}$.This is important as "physical access to food", i.e. consumers being able to access food, and farmers being able to get their produce to the consumer, is an important part of food security. Physical access has been seriously affected in many countries. The COVID-19 pandemic if allowed to run longer has potential to affect the nutrition aspect of food security ${ }^{3}$.

\section{Materials and Methods}

It was a systemic review study regarding global food security status due to COVID-19. We gather total 29 articles and web portals information related to COVID-19 and food security using different search portal like PubMed, Google Scholar, Nature, and Lancet. After proper literature review only 9 literatures and web portals information which were related to this study were taken for this systemic review purpose.

\section{Results}

In India and elsewhere, agricultural produce are either being dumped, fed to livestock or left to rot. All because farmers cannot harvest their produce or transport them to market due to movement control or "lockdown". In China and Malaysia, restrictions have been put in place to limit consumer access to supermarkets and other food retail outlets. This is important as "physical access to food", i.e. consumers being able to access food, and farmers being able to get their produce to the consumer, is an important part of food security. Physical access has been seriously affected in many countries due to movement control or "lockdown"3.

The COVID-19 pandemic has proven to be a wakeup call for Singapore on the issue of food security as about 90 per cent of Singapore's food currently comes from overseas. Singapore and six other countries - namely Australia, Brunei, Canada, Chile, Myanmar and New Zealand - issued a joint ministerial statement highlighting a commitment to 
maintaining open supply chains amid the ongoing pandemic ${ }^{4}$.

Developing countries, particularly small island development states (SIDS), dependent on tourism have already experienced a precipitous collapse in their revenues given that international travel has come to a halt. These losses make it more difficult to pay for the imported food required for survival in these countries. Cereals imports are spread across a very large number of countries in all regions - China alone accounts for more than $5 \%$ of total imports whereas only a handful of countries account for the bulk of cereals exports. In China, the biggest importer of soybeans, soybean futures prices increased by $5 \%$ between 27 March and 30 March. Soymeal, soy oil, palm oil and other food commodities also saw price increases. The United States and the Russian Federation alone represent a quarter of cereals exports. Adding exports by India, Argentina, Australia and Ukraine, a total of six countries where COVID-19 is in its expansion phase account for more than half of total cereals exports. Kazakhstan and Viet Nam have suspended exports of wheat flour and rice, respectively, as a result of COVID-195.

In Latin America and the Caribbean, FAOsupported school meals programmes benefit 85 million children. Some 10 million children depend on them as the meals constitute one of their most reliable sources of food each day. The suspension of the school meals programs due to the pandemic puts vulnerable children's food security and nutrition at risk whilst weakening their capacity to cope with diseases. Fish provide more than 20 percent of the average per capita animal protein intake for 3 billion people, more than 50 percent in some less developed countries, and it is one of the most traded food commodities globally. Thus, the impact on the livelihoods of fisher communities, food security, nutrition and trade, especially in those countries, which rely heavily on the fishing sector, is expected to be significant ${ }^{2}$.

Kenya imports about $90 \%$ of the total rice demand and about $75 \%$ of the total wheat demand. The rest is produced locally. The coronavirus outbreak adds to the challenge because markets have been closed and delivery of food has been disrupted ${ }^{6}$.

\section{Discussions}

\section{Hotspots of Food Security}

Food security "hot spots" include:

- Fragile and conflict-affected states, where logistics and distribution are difficult even without morbidity and social distancing.

- Countries affected by multiple crises resulting from more frequent extreme weather events and pests. Example: the current locusts plague - the worst in decades - is severely impacting food security in 23 countries.

- The poor and vulnerable, including the more than 820 million people who were already chronically food insecure before the COVID-19 crisis impacted movement and incomes.

- Countries with significant currency depreciation, driving up the cost of food imports $^{7}$.

\section{Impact of COVID-19 on food security and nutrition}

The COVID-19 pandemic is already affecting food systems directly through impacts on food supply and demand, and indirectly through decreases in purchasing power and in the capacity to produce and distribute food, which will have differentiated impact and will more strongly affect the poor and vulnerable. Potential risk for global food availability and food prices will depend on the duration of the outbreak and the severity of containment measures needed. Isolated country level policies are likely to amplify the effects of the crisis on food security and nutrition at the global level, especially for developing and food-insecure countries. Further, the potential impact of the pandemic on food production in major food producing countries (e.g. China, EU, USA) could have serious implications for global food availability and food prices ${ }^{8}$. 


\section{Impact of COVID-19 on food supply and demand}

COVID-19's impacts on food supply and demand will directly and indirectly affect all four pillars of food security and nutrition. It is also expected that there will be immediate effects resulting from the containment measures adopted in several countries, and these measures will also havelonger-term effects affecting the full global economy ${ }^{8}$.

\section{Impact on food supply}

As caseloads of COVID-19 increase in countries around the world, there are likely to be disruptions to agri-food supply chains. Although there may have been plenty of food within the supply chains at the start of the crisis, disruptions to food supplies have tracked outbreaks due to a rise in panic buying by people concerned about food supplies during potential lockdowns. If outbreaks around the world are severe or continue over long periods of time, there are likely to be even more serious disruptions that may reduce food availability in the markets over the medium and longer terms. These disruptions may occur as a result of producers themselves becoming ill or because of disruptions to markets due to policies to contain the virus. Declining demand due to a decline in purchasing power will in turn affect the ability and willingness of farmers and producers to invest and adopt adequate technology and will further shrink food production and availability . $^{8}$

\section{Impact on Food Demand}

Starting with the containment and social distancing policies, the pandemic creates first a spike in demand, due to panic buying and hoarding of food by consumers, which will increase food demand in the short term. However, this spike in purchases can be followed by a declining trend in demand, both in terms of physical ability to purchase food, and in terms of loss of income and purchasing power linked to the loss of jobs and the freezing of economic sectors. Changes in short term preferences due to perception in food safety or convenience can become long-term changes, with repercussions on food systems, livelihoods of food producers and dietary diversity ${ }^{8}$.

\section{Impacts of COVID-19 on Farmers}

In many ways at once. For example, the U.S. agricultural system is facing severe labor challenges. According to the American Farm Bureau, among farmers' and ranchers' biggest Covid-19-related concerns is the availability of farm labor, since much of it is sourced through the $\mathrm{H}-2 \mathrm{~A}$ visa program that was temporarily suspended in response to the Covid-19 pandemic. In late March, the U.S. State Department moved to ease the H-2A restrictions. (Labor constraints could lead to lower supply of, and thus higher prices for, farm inputs like fertilizer, seeds, and animal feed, all of which would eat away at farmers' bottom lines.) On April 17, the U.S. Department of Agriculture (USDA) announced the Coronavirus Food Assistance Program (CFAP). The two major elements of the program include $\$ 16$ billion of direct support for farmers and ranchers, and procurement by USDA of $\$ 3$ billion in fresh produce, dairy, and meat originally destined for outlets like restaurants that have temporarily or permanently closed. The outlook for farmers in low- and middle-income countries, where agriculture accounts for a greater share of GDP, relative to wealthier countries is worse. As a recent piece from the Agricultural Market Information System points out, agriculture in these countries is labor-intensive, so quarantine measures, self-isolation, and a version behavior in response to an outbreak "would therefore cut the labor supply, potentially resulting in acreage contractions, limiting crop management and ultimately curbing harvests ${ }^{9}$.

\section{Conclusion}

The devastating economic impacts of COVID-19 reinforce the need for investments that prevent future outbreaks of such infectious diseases, recognizing the interconnections between people, animals, plants and their shared environment - the One Health approach. Continued attention is 
necessary strengthen the resilience of food systems to such disease outbreaks but also to other shocks.

\section{Recommendations}

1) Governments may need to support food supply chains to ensure that they function smoothly in the face of the crisis in order to stabilize food systems so that they can support food security and nutrition.

2) National governments should encourage local communities and citizens to increase local food production (including home and community gardens), minimize food waste, and refrain from panic buying.

3) Governments should provide advice tailored for food workers involved in food production, handling and processing to help avoid catching and spreading COVID-19.

4) Social protection mechanisms for the poorest and most vulnerable people during the COVID-19 crisis need to be employed that incorporate provisions on the Right to Food. These mechanisms should provide essential assistance in the short term and support livelihoods in the long term.

\section{References}

1. COVID-19 Pandemic : World Food Programme: access on: 26/04/2020

Available

https://www.wfp.org/emergencies/covid-19pandemic

2. Novel Corona Virus Disease 2019 : Food and Agricultural Organization of United States: access on: 26/04/2020

Available at: http://www.fao.org/2019ncov/q-and-a/impact-on-food-andagriculture/en/

3. COVID-19: Maintaining Food Security in Asia Pacific : Inter Press Service News Agency: access on: 24/04/2020

Available at: https://www.ipsnews.net/2020/04/covid-19maintaining-food-security-asia-pacific/
4. COVID-19 pandemic highlights importance of strengthening Singapore's food security : Channel News Asia: access on: 20/04/2020 Available at:

https://www.channelnewsasia.com/news/sin gapore/covid10-singapore-food-securityfarming-innovation-12649468

5. COVID-19 and food security in vulnerable countries: United Nations Conference on Trade and Development: access on: 19/04/2020. Available at:

https://unctad.org/en/pages/newsdetails.aspx ?OriginalVersionID=2331

6. Why COVID-19 is another blow for Kenya's food security: The Conservation: access on: 21/04/2020 Available at: https://heconversation.com/why-covid-19is-another-blow-for-kenyas-food-security135567

7. Food Security and COVID-19: The World Bank: Access on: 18/04/2020 Available at: https://www.worldbank.org/en/topic/agricult ure/brief/food-security-and-covid-19

8. Impact of COVID-19on Food Security and Nutrition: Committee of World Food Security. Available at: https://fscluster.org/sites/default/files/docum ents/2020-03-19._impact_of_covid19_on_fsn_-_hlpe_-_final_draft.pdf

9. Covid-19 and Food Security: Center for Strategic and International Studies: access on: 18/04/2020 Available at: https://www.csis.org/programs/global-foodsecurity-program/covid-19-and-foodsecurity 